\title{
ERRATUM
}

Journal of the Chilean Chemical Society, Volume 56 NNo $^{\circ}, 546-548$ (2011)

\section{HYDROGEN-BONDED SUPRAMOLECULAR ARRAY IN \\ THE CRYSTAL STRUCTURE OF ETHYL 7-HYDROXY-2-OXO-2H-CHROMENE-3-CARBOXYLATE MONOHYDRATE}

\author{
ANTONIO GALDÁMEZ, , * OLIMPO GARCÍA-BELTRÁN ${ }^{1}$ AND BRUCE K. CASSELS ${ }^{1,2}$ \\ ${ }^{1}$ Departamento de Química, Facultad de Ciencias, Universidad de Chile. \\ Casilla 653, Santiago, Chile \\ ${ }^{2}$ Millennium Institute for Cell Dynamics and Biotechnology, Santiago, Chile
}<smiles>CCOC(=O)CC(=O)OCC</smiles>

Scheme 1. Reagents and conditions: (a) $\mathrm{POCl}_{3}$, DMF, ACN, 2 h; (b) piperidine, $\mathrm{AcOH}, \mathrm{EtOH}$, reflux, 6 h. 